\title{
The Ethics in Substitution Treatment and Harm Reduction. An Analytical Review
}

\author{
Carmen Aceijas, $\mathrm{PhD}^{1}$
}

\begin{abstract}
The ethics of opiate substitution treatment (OST) modalities for heroin addiction have been abundantly criticised but also have equally strong supporters. This analytical review addresses three main arguments against such treatments: 1) the social nature of the issue involves a misuse of the medical care; 2) the aim is one of social control (as opposed to a "cure") and therefore is a perversion health care; and 3) prescribing the very substance (or a substitute) that caused the addiction is ethically questionable. Additionally, the generic criticism against the philosophical/ theoretical framework under which they operate, "harm reduction" (HR) as an operational goal of therapy, is also addressed here.

A summary review of the history of addiction supports the argument that, indeed, drug addiction "as a problem" was socially created. Equally clear is that one of the aims of OST and all drug-addition treatments is the social control of individual behaviours. However, neither of these two aspects justifies refusal to provide health and social care. OSTs are legitimate therapeutic options because they comply with the four principles of bioethics-autonomy, nonmaleficence, beneficence and justice. The argument that such treatments and the HR approach, in general, align with the principle of consequentialism - the aim justifies the means - and therefore is ethically questionable is a disingenuous criticism. Consequantialism is based in the implicit assumption that harms are accepted to reach certain objectives as the lesser of two evils. OSTs have been extensively proven as to their safety with benefits margins both at the individual (retention, reduction of illicit drug use and better social adjustment) as well as at the population levels (e.g., HIV incidence reduction). Heroin-substitution based treatment is the latest case of moral resistance to provide patients with the most effective option in spite of sound evidence on its effectiveness and safety. As in other cases of spurious resistance to public health and medical innovations, it is only a matter of time and endurance until such treatments are fully integrated among standard therapeutic options for heroin dependent individuals.
\end{abstract}

\footnotetext{
${ }^{1}$ Salford University, School of Health Sciences, Salford, Greater Manchester, UK.

Corresponding Author Contact Information: Carmen Aceijas at c.aceijas@salford.ac.uk, Salford University, School of Health Sciences, Allerton Building, Room L812a, Frederick Road Campus, Salford, Greater Manchester, M6 6PU, UK.
} 
Key Words: Ethics, bioethics, addiction, opiate substitution treatment, OST, harm reduction

Suggested Citation: Aceijas C. The ethics in substitution treatment and harm reduction. An analytical review. Public Health Reviews. 2012;34: epub ahead of print.

\section{INTRODUCTION}

Ethical issues concerning the consent of drug addicts to treatment and research, ${ }^{1}$ to the acceptability of legally coerced treatment for drug use offenders, ${ }^{2}$ with reflections on ethics and drug misuse treatment, have extensively populated scientific and non-scientific literature. Opiate substitution treatments (OST) for heroin addiction have been profusely criticised using multiple arguments and to address them all would require a review far more extensive than the possibilities a single paper allows. This paper focuses on ethical issues related to OST for heroin dependence and their theoretical framework; harm reduction (HR). It is an analytical review addressing three of the main arguments against such treatments: One of the criticisms around the medical provision of a substitution substance for heroin users revolves around the social nature (not necessarily medical) of the issue. Thus, in the 1980s a series of papers argued that heroin dependence was not clearly a medical issue because it was a socially created problem and therefore, medical care was, somehow inappropriate or misused. ${ }^{3}$ Another of the arguments against OST is based on the assumption that their purpose is one of social control ${ }^{4}$ (as opposed to a "cure") and therefore it is a perversion or deviation from what health care professionals should be aiming for. A third argument questions the ethical foundations of prescribing the very substance (or a synthetic substitute) that caused the addiction in the first place. ${ }^{5}$ These arguments have been used not only against OST but also to counter the philosophical and theoretical framework under which they operate; the HR approach to drug misuse. ${ }^{5}$ Therefore, a reflection about this extension-of-the-critique is also included here.

\section{THE SOCIAL NATURE OF ADDICTION}

Substance abuse was not conceptualized as a medical problem but a "vice" or "habit" till well into the $20^{\text {th }}$ century, and the intricate relationships between drug misuse and medicine are something of a new phenomenon that for years was pushed away from the sphere of professionalised health care. Quite simply, since it was not an illness, it was not a medical problem. Public health itself is a relatively young discipline formally structured for 
years around biomedical concepts in the success of the supporters of the germ theory (i.e., social-environmental causation of disease) and, thus, the above medical argument was extended to public health, i.e., since addiction was not an illness, it was not a public health concern either.

Opium, however, is a substance with centuries of tradition in most known cultures with a written legacy of their citizen habits. In the Middleand Far-East, opium was a reputed painkiller for centuries. Europe learnt about opium in the context of the European colonies in the $18^{\text {th }}$ century and it eventually became a main ingredient in patent medicines. There have been historical episodes where utilisation of morphine as a pain reliever was well documented (e.g., America Civil War). ${ }^{6}$ During the $19^{\text {th }}$ century many years of war were fought over the opium trade, especially promoted by the British Empire in a compliant market in China with millions of opium addicts and with serious geopolitical consequences lingering to the present time.

It is this historical period from which the first estimates of populations addicted to opium emerge: By 1900, over 200,000 people in the United States were addicted to opium. ${ }^{7}$ But it is not until the early years of the past century when the first legislation concerning opium and aiming at an orderly marketing of opium, morphine, heroin, and other drugs in small quantities was passed: the US 1915 Harrison Narcotic Act. An interesting interpretation of the context and extension of the Act argues that it protected the right of a physician to prescribe these drugs. The negative consequences on health care provided to addicts were observed immediately after its implementation, as the outcome of a gross misreading of the Act. While the Act specifically reads "Nothing contained in this section shall apply... to the dispensing or distribution of any of the aforesaid drugs to a patient by a physician, dentist, or veterinary surgeon registered under this Act in the course of his professional practice", the interpretation of the last words "professional practice" brought about unexpected consequences, since, as described earlier, addiction was not considered at that time to be an illness. Thus, a physician prescribing opium or its derivates for morphine dependent patients was acting beyond the boundaries of his professional practice. ${ }^{6,8}$ Another diametrically different interpretation however, places harsh responsibility for this conundrum on the medical profession partially attributing the writing of the Act itself to medical lobby efforts. ${ }^{9}$

In any case, the immediate aftermath of the Harrison Act was already reported in less than a year; "As was expected... the immediate effects of the Harrison antinarcotics law were seen in the flocking of drug habitués to hospitals and sanatoriums. Sporadic crimes of violence were reported too, due to desperate efforts by addicts to obtain drugs, but occasionally to a delirious state induced by sudden withdrawal..." ${ }^{\prime \prime}$ A number of scientific, 
policy and press documents provide intelligent insight into an acute intensification of a problem not felt or reported as such prior to the passage of the Act. Only three years later, the explosive growth of the practice of drug use was seen from a previously estimated 200,000 addicts to an increase to approximate one million people in the US. The relationships between the very existence of the Act (or its misinterpretation) and the increased number of addicts and the deterioration of their living conditions and health status was reported at the highest levels by US congressman Homer T. Rainey in 1918 when reporting to the appointed committee to look into the claims of the worsening situation; "The wrongful use of narcotic drugs had increased since passage of the Harrison Act. Twenty cities, including New York and San Francisco, had reported such increases." ${ }^{11}$ A war on drugs, as we know it nowadays, was declared and its collateral damages widely reported throughout the years. An example of such reads: "Drugs are a commodity of trifling intrinsic value. All the billions our society has spent enforcing criminal measures against the addict have had the sole practical result of protecting the peddler's market, artificially inflating his prices, and keeping his profits fantastically high... No other nation hounds its addicts as we do, and no other nation faces anything remotely resembling our problem." ${ }^{\prime 2}$ And they have reached contemporary times: "Despite the fact that patterns of drug consumption have always varied between the 25 European Union Member States, especially in respect of scale, new problems have emerged in some areas, and there are no data to suggest a significant fall in drug use."13

This very brief account of how opium use became a problem, should serve as a basis to acknowledge that one cannot deny the magnitude of the social gradient of drug misuse. The critics of OST were, indeed right in the sense that heroin dependence as "problem" was created in a social niche of punitive actions targeting those who were dependent on morphine.

\section{SUBSTITUTION TREATMENT AS A SOCIAL CONTROL TOOL}

Another of the arguments against OSTs for heroin dependence is based on the assumption that their real aim is one of social control (as opposed to a "cure"). Once again, this author wishes to acknowledge the truth in this argument.

This leads us into a discussion of the second of two important and linked points used in the rejection of OST: addiction is a socially created and maintained problem yet medicine is asked to address it as a health problem with medical tools (presented above) when in fact the true aim of 
these treatments is social control and the use of medical care is allegedly a perversion of its real aim (to cure).

While it is hard to deny the supportive role of health care provided to drug addicts in the minimisation of the many social problems associated with drug abuse and therefore impossible not to acknowledge their quality as social control tools, the same can be said about all drug addiction treatments. Social control is not exclusively terrain for OST. From preventive to punitive measures, all interventions tackling drug misuse, can be seen as tools of social control.

Furthermore, the same can be said for multiple health issues that affect especially the so called "developed world" and are classified as "life-style" related health problems in which health care strategies involve some element of social control. Why should it be surprising? The fundamental importance of the social determinants of ill health is universally acknowledged and we tackle health problems that affect large sectors of the population as public health problems that need to be addressed in their biological as well as in their social aspects. Thus, interventions tackling obesity, to use a major health problem as correlate of this line of argumentation, such as food labeling, mass-media campaigns, school-based programs and many others, are not interventions to which the public opts for voluntarily. One cannot request unlabelled food in the supermarket, one cannot demand TV without "healthy eating" messages (sadly one cannot ask for TV without unhealthy eating advertisements either). Populations are exposed to health information/ education attempting to control the worrying epidemic of obesity. At the end of the day, the intention is to try to control individual behavior. Why are these measures not seen, judged and rejected as tools of social control? How then does no one launch campaigns claiming that medicine or public health should not be used to tackle overweight and obesity related problems because they are social as well as individual problems? I rest my case.

Thus, we can conclude that, yes, those who remind us of the social nature of drug misuse and the aim of social control embedded in OST, are correct. The only weakness in such arguments is that none of these features justify rejection of such therapeutic options.

\section{PROVIDING USERS WITH A SUBSTANCE LIKE THAT WHICH CREATED THE ADDICTION IS UNETHICAL}

What justifies OST for heroin dependent individuals, is that in all its three more widely known modalities - methadone, buprenorphine and medicallyprescribed heroin-it complies with the four principles of bioethics. 
Bioethics, as one of the existing moral theories, refers to the ethics that guide biology, biological research and its applications. As ethical theory, bioethics brings together disciplines such as medicine, law, social sciences, philosophy, theology and politics to address medical research and clinical decision issues. ${ }^{14}$ The main principles of bioethics are: autonomy (acknowledgement and respect for the right of individuals to make their own decisions), nonmaleficence (any intervention should, first of all, not cause harm) beneficence (the active steps to help others) and justice (benefits and risks should be fairly distributed). ${ }^{15}$ The ethical legitimacy of a given treatment intervention is measured by its capacity to demonstrate that it is ethically sound, in that it complies with these four main principles of bioethics. Although recent literature sets out differences between bioethics and ethics associated with population health, as discussed elsewhere in this journal issue.

OST respects the autonomy of patients to the extreme in that it acknowledges: first, that heroin addicts are entitled to and fully capable of taking their own decisions including those around how best to tackle their addiction; and secondly, that this right to decide includes the non abandonment of the consumption or the intake of a substitute even if it means the continuation of the addiction, i.e., with the lesser of two evils.

The principle of nonmaleficience is also preserved. Starting from the pioneer 22 patients study of Done and Nyswander, which first demonstrated in 1965 that the use of methadone is a safe and effective way to clinically manage heroin addiction, ${ }^{16}$ all three substitutes mentioned earlier have been/ are submitted to extensive clinical trials and other forms of research to test their safety and effectiveness levels. To date, the research has demonstrated ample safety margins with no harm attributable to the medically prescribed substitute and remarkable levels of effectiveness regarding different outcome measures (reduction of severity of addiction, criminality levels and streetacquired heroin, social adjustment improvement, cost-effectiveness and so on). ${ }^{17,18}$

Furthermore, OST follows the principle of beneficence as it provides active and specific help to all those individuals whom, at some point in their addiction history, do not feel prepared to give up their addiction. One must remember that part of the success of these therapeutic options is based in the fact that they have been successful in retaining within the health and social services networks, populations of addicts, otherwise hidden populations, out of contact and out of reach. In other words, entry through the door of substitution treatment creates many other openings to access health and social care. No other treatment modalities have demonstrated this capacity to such an extent as OST. 
Finally, the principle of justice is satisfied as all the possible risks arising from the provision of a substitute substance are not only published but duly addressed. OST does not operate under an umbrella of false riskabsence. It is acknowledged that as long as the active addiction persists, there is a problem. However, when balancing the two too often realistic options: leaving the person suffering from an addiction and unwilling or incapable at a given moment of his/her life to give up drugs, outside of any net of treatment and care or providing a safe substitute paired with an array of health strategies and interventions from the lowest and very important level of pure contact with health services which will, at least, preserve and stabilize the baseline quality of life thus, avoiding further deterioration and in the overwhelming number of cases, improving both physical and mental health and social conditions, the option is clear.

\section{IS THE PROBLEM OST OR THE HARM REDUCTIONAPPROACH?}

Another important debate around OST has to do not specifically with these particular treatments but to the HR philosophical umbrella under they were classified. HR is, to use one of the oldest and more widely quoted definitions "a term that defines policies, programmes, services and actions that work to reduce the: health, social and economic harms to individuals, communities and society." 19 OST has traditionally been, and partially wrongly, classified under the HR interventions and strategies. One may say "partially wrongly" because strictly speaking HR interventions are those that do not target the consumption itself, but the conditions and circumstances under which the drug use happens. Since OST does target consumption itself, its intrinsic nature is interventionist and thus it is not fully compliant with HR. Nevertheless, the ethical questioning of OST as seen as HR treatments is not directed to the specific provision of one substance or another but questions the legitimacy of allowing an individual to continue the intake of a substance that has, directly and/or indirectly, damaged his/her health and quality of life.

The well-established principles of $\mathrm{HR}$ — pragmatism, goal prioritization, humanism, focus on harms and risks, no focus on abstinence and maximization of the range of available intervention options ${ }^{20}$ - have been portrayed as weak and evidence of a defeatist attitude towards drugs. They, however obviously match the main principles of bioethics in health care.

Still, the added value of HR measures such as the distribution of sterile injecting equipment and the provision of substitution treatments, experienced the counter-attack argument that the "aims do not justify the means". Their 
rationale questioned the HR interventions as being too closely related to one of the major ethics schools of thought, consequentialism and its motto "because it justifies the means". But, does it not?

The principles of consequentialism have been have criticized with many good reasons, the first being the dubious acceptance of harm to some in order to benefit others. However, when referring to OST such a dilemma simply does not exist. The provision of OST does not harm some for the benefit of others. It simply does not cause harm. As elucidated earlier, it fully complies with the principle of nonmaleficence and therefore, it is one scenario in which, indeed, the aims do not only justify the means, they welcome them.

Furthermore, despite rivers of ink flowing against OST for years (as betraying the holy goal of making people "free from drugs"), from the moment the HIV/AIDS epidemic reached epidemic proportions, the well intentioned, however judgmental, speeches about the unethical nature of OST (as treatments based in the provision to users with the drug of abuse as a main cornerstone of the treatment), were simply made redundant. The risks of association of drug abuse with intravenous drugs and passage of HIV and hepatitis B and C were overwhelming evidence for the need of risk reduction programs as a basic tool to prevent the spread of diseases, as in the distribution of clean needles for injection and condoms to prevent sexual transmission of these diseases.

The justification of HR approaches from a public health perspective was sadly not only linked to the increase of heroin dependent populations during the 1970s and 1980s but also to the outbreak of HIV/AIDS in western societies, which by the mid 2000s have reached pandemic levels worldwide. ${ }^{21}$ In many countries the epidemic was clearly driven by unsafe injecting practices among heroin dependent individuals eventually crossing over into other populations through risky sex practices. In this context, OSTs, mainly methadone and buprenorphine, were given a very important mandate; to stop the spread of the infection by reducing the number of injections required to satisfy the addiction, and it did work.

\section{HEROIN SUBSTITUTION THERAPY}

The latest development in OST is the initiative of providing heroin addicts with medically prescribed heroin. In spite of the benefits from methadone and buprenorphine, there are individuals for whom such therapeutic options do not seem to work. Reasons vary but, more so than a biological resistance to treatment with long-life substitute opiates (described among, for instance, 
rapid metabolisers), the predominant case of failure of treatment is the combined effect of social and individual factors. Moreover, repeated failures in methadone treatment might suggest no more than a temporary problem with succeeding in treatment that does not necessarily predict a negative outcome in methadone treatment for the rest of the person's life. Thus, heroin treatment was designed for those to whom, at a given time in their lives, methadone treatment does not seem to work.

When presented with the proposal of offering medically prescribed and supervised heroin to those patients, different countries seemed to unanimously react with the "give me evidence" requirement. Thus, a number of countries have implemented clinical trials to test the safety and effectiveness of heroin treatment. Time and millions have been spent to dress up with science what common sense would conclude: it is safer and healthier than the heroin in the streets. ${ }^{22}$

The benefits, as detected with meta-analysis, include improvement in retention in treatment and reduction of consumption of illicit drugs plus reduction of criminal activity and improvement of social adjustment. ${ }^{18}$ Beyond meta-analysis, findings from individual trials have been conclusive and remain undisputed. However, none of the countries that commissioned such studies have changed their policies despite the research outcomes. Switzerland (from 1995), the pioneer country in the study of this therapeutic option, started the prescription in parallel to a cohort study. ${ }^{23}$ The United Kingdom study did not affect the situation either: medical prescription has always been legal and a number of general practitioners keep prescribing heroin as per standard practice. ${ }^{24}$ Spain, ${ }^{25}$ the Netherlands (2000), ${ }^{26,27}$ Germany (2002) ${ }^{28}$ and Canada' ${ }^{29}$ policies regarding the provision of heroin treatment remain unchanged years after the completion of their trials.

In these situations, concerns regarding the ethical foundations for the non adoption of such treatments within the national health systems should be questioned. What is more than evident is that drug treatments that go beyond the narrow constrains of the "drug-free" goal are constantly asked to produce scientific evidence. Yet the principles of science and how they are used in the adoption of new treatment modalities do not seem to apply to OSTs. As Small and Drucker rightly pointed out in 2006 "if a new drug for breast cancer or colon cancer were shown to be as efficacious and effective as heroin has been shown to be, the clinical trial would generally be stopped and the medical program with ongoing scientific evaluation would commence immediately." 30

The positive aspect of the situation as it currently stands for heroin substitution therapy is that the historical memory of those committed to 
care and research in the areas of addiction gives them reason for optimism. OST was seen as evil upon its introduction, yet overwhelming evidence about its benefits both at individual and population levels made its consolidation as standard treatment unavoidable. It is only a matter of time that heroin substitution treatment will be recognized and implemented as part of the normalized standard therapeutic strategies used for the treatment of those who suffer from heroin addiction. The ethical values of such options are undeniable and health care, medicine and public health have a longstanding tradition of, against all odds, surrendering to evidence.

\section{Acronym List:}

$\mathrm{HR}=$ harm reduction

OST $=$ opiate substitution treatment

About the Author: Dr. Carmen Aceijas studied Psychology as an undergraduate and developed a taste for research in health and a specific interest in drug misuse, volunteering in prisons and drug-treatment centres. Soon after, she took a position in the Andalusian School of Public Health (EASP) in a regional evaluation of methadone programs, transitioning from Health Psychology to Public Health. During her years of training as a public health researcher at EASP, Dr. Aceijas was involved with the "Clinical Trial of Diacetylmorphine for the treatment of heroin dependence among injecting drug users" and the "Evaluation of Methadone Treatment Programs in Andalusia [ETMA]". The latter served as the basis for her $\mathrm{PhD}$ in 2005 awarded by the University of Granada in partnership with Imperial College, London on "Attitudes of professionals working in drug treatment centres towards methadone treatment". In 2002, Dr. Aceijas moved to the UK for the UN founded project, "HIV/AIDS among IDUs in developing and transitional countries" first at Imperial College and later at the London School of Hygiene and Tropical Medicine [LSHTM]. With this work, she developed a specific interest in Research Synthesis and Evidence Based Public Health, publishing a series of systematic literature reviews on different epidemiological aspects of drug misuse and HIV.

Conflicts of Interest: None declared.

\section{REFERENCES}

1. Buchman DZ, Skinner W, Illes J. Negotiating the relationship between addiction, ethics, and brain science. AJOB Neurosci. 2010;1(1):36-45.

2. Hall W, Lucke J. Legally coerced treatment for drug using. offenders: ethical and policy issues. Crime and Justice Bulletin. NSW Bureau of Crime Statistics and Research. Contemporary Issues in Crime and Justice. No 144. September 2010.

3. Have HT Sporken P. Heroin addiction, ethics and philosophy of medicine. J Med Ethics. 1985;11:173-7. 
4. Access. An 'inside' view of methadone. Newsletter of the access project sharing knowledge and good practice. Winter 2011/12. Issue 1. p.7.

5. Elovich R, Drucker E. On drug treatment and social control: Russian narcology's great leap backwards. Harm Reduct J. 2008;5:23.

6. Casey E. History of drug use and drug users in the United States. From Facts About Drug Abuse - Participant Manual - The National Drug Abuse Center for Training Resource and Development. 1978. Available from URL: http://www. druglibrary.org/schaffer/history/casey1.htm (Accessed 21 November 2012).

7. Kandall SR. Women and addiction in the United States - 1850 to 1920. In: Substance and Shadow: A History of Women and Addiction in the United States -1850 to the Present. Cambridge, MA: Harvard University Press; 1999.

8. Public Acts of the Sixty-Third Congress of the United States. Harrison Narcotics Tax Act, 1914. Public law no. 223. Approved, December 17, 1914. Available from URL: http://www.druglibrary.org/Schaffer/history/e1910/harrisonact. htm (Accessed 21 November 2012).

9. Courtwright D. Dark Paradise: Opiate Addiction in America before 1940. Cambridge, MA: Harvard University Press; 1982.

10. New York Medical Journal Editors. Mental sequelae of the Harrison Law. N Y Med J. 1915;102:1014.

11. Rainey HT, (Congressman). Chairman to the Committee appointed to look into the claims about the worsening situation. 1918. In: Brecher EM, et al. The Consumers Union Report on Licit and Illicit Drugs. Chapter 8. The Harrison Narcotic Act (1914). 1972. Available from URL: http://www.druglibrary.org/ schaffer/library/studies/cu/cu8.html (Accessed 21 November 2012).

12. King R. The Yale Law Journal. 1953. In: Brecher EM, et al. The Consumers Union Report on Licit and Illicit Drugs. Chapter 8. The Harrison Narcotic Act (1914). 1972. Available from URL: http://www.druglibrary.org/schaffer/ library/studies/cu/cu8.html (Accessed 21 November 2012).

13. Council of European Union. EU drug strategy, 2005-2012. Brussels, Belgium: 22 November 2004. p.4.

14. PHG Foundation. Moral theories - introduction. 2008. Available from URL: http://www.phgfoundation.org (Accessed 21 November 2012).

15. PHG Foundation. Moral theories - principles of bioethics. 2008. Available from URL: http://www.phgfoundation.org (Accessed 21 November 2012).

16. Dole VP, Marie Nyswander M. A medical treatment for diacetylmorphine (heroin) addictiona clinical trial with methadone hydrochloride. JAMA. 1965;193:646-50.

17. Connock M, Juarez-Garcia A, Jowett S, Frew E, Liu Z, et al. Methadone and buprenorphine for the management of opioid dependence: a systematic review and economic evaluation. Health Technol Assess. 2007;11:1-171, iii-iv.

18. Ferri M, Davoli M, Perucci CA. Heroin maintenance for chronic heroindependent individuals. Cochrane Database Syst Rev. 2010;(8):CD003410. JohnWiley \& Sons, Ltd.; 2012. 
19. Newcombe R. The reduction of drug related harm: a conceptual framework for theory, practice and research. 1992. Available from URL: http://www. drugtext.org/Various-general/the-reduction-of-drug-related-harm-aconceptual-framework-for-theory-practice-and-research.html (Accessed 21 November 2012).

20. The Canadian Centre on Substance Abuse (CCSA). 1996. Available from URL: http://www.ccsa.ca/Eng/Pages/Home.aspx (Accessed 21 November 2012).

21. Aceijas C, Stimson GV. Hickman M, Rhodes T. Global overview of injecting drug use and HIV infection among injecting drug users. AIDS. 2004;8:2295303.

22. Trujols J, Aceijas C. El reinado del ensayo clínico controlado y la ética paternalista. [The randomized clinical trial's kingdom and the paternalistic ethic]. Centro de Documentación de Drogodependencias (CDD). November 2003; 101. Available from URL: http://www.gizartegaiak.ej-gv.net/Gizarte GaiakContenidos/pdf/revista/revista\%20n.101.pdf (Accessed 21 November 2012). [In Spanish]

23. Uchtenhagen A, Dobler-Mikola A, Steffen T, Gutzwiller F, Blättler R, Pfeifer S, (editors). Prescription of narcotics for heroin addicts: main results of the Swiss National Cohort Study. Basel: Karger Verlag; 1999.

24. Strang J, Metrebian N, Lintzeris N, Potts L, Carnwath T, Mayet S, et al. Supervised injectable heroin or injectable methadone versus optimised oral methadone as treatment for chronic heroin addicts in England after persistent failure in orthodox treatment (RIOTT): a randomised trial. Lancet 2010; 375:1885-95.

25. March JC, Oviedo-Joekes E, Perea-Milla E, Carrasco F, PEPSA team. Controlled trial of prescribed heroin in the treatment of opioid addiction. J Subst Abuse Treat. 2006;31:203-11.

26. van den Brink W, Hendriks VM, van Ree JM. Medical co-prescription of heroin to chronic, treatment-resistant methadone patients in the Netherlands. J Drug Issues. 1999;29:587-608.

27. van den Brink W, Hendriks VM, Blanken P, Koeter MWJ, van Zwieten BJ, van Ree JM. Medical prescription of heroin to treatment resistant heroin addicts: two randomised controlled trials. BMJ. 2003;327:310-6.

28. Haasen C, Verthein U, Degwitz P, Berger J, Krausz M, Naber D. Heroin-assisted treatment for opioid dependence: randomised controlled trial. Br J Psychiatry. 2007;191:55-62.

29. Oviedo-Joekes E, Brissette S, Marsh DC, Lauzon P, Guh D, et al. Diacetylmorphine versus methadone for the treatment of opioid addiction. N Engl J Med. 2009;361:777-86.

30. Small D, Drucker E. Policy makers ignoring science and scientists ignoring policy: the medical ethical challenges of heroin treatment. Harm Reduct J. 2006;3:16. 